\title{
POESIA “PARABÍBLICA” EN EL VERB DE JOSEP CARNER: UN ESTUDI LITERARI
}

\author{
EULÀLIA VERNET I PONS
}

\begin{abstract}
This article discusses eight poems of biblical influence written by Catalan poet Josep Carner published in 1957 in Verb. These poems, together with Nabi, his most extensive poem, were inspired by different episodes and characters of the Old Testament. This essay pays special attention to the influence of the Old Testament in Carner's work as well as his use of other biblical sources by carrying out a formal, stylistic, and critical analysis of the poems.
\end{abstract}

\section{INTRODUCCIÓ}

L'article que presento a continuació analitza la presència i la influència de l'Antic Testament en els versos de Josep Carner, el poeta que s'inspira en els diferents llibres de la Bíblia per expressar, amb l'ús de la paraula, la connexió de l'home amb si mateix, amb l'altre i amb Déu.

L’obra poètica de Josep Carner està fornida de reminiscències bíbliques, de versos que traspuen l'esperit creient del poeta. ${ }^{\mathrm{I}}$ Aquesta fe i esperança traspassen metafòricament molt sovint el sentit dels seus versos i s'adapten patriòticament a la realitat política i social del país (veg., en aquest sentit, el comentari corresponent als poemes següents: "Salm de la captivitat", "Els patriarques" $i$ "Els profetes"). Fe i esperança, cristiana i patriòtica, doncs, s'alcen com a dues constants en el poeta, dues característiques que l'estudiós ha de tenir present per a poder aprofundir en la seva obra.

Quant als versos de tradició bíblica, en el contingut dels llibres i colleccions de l'obra completa de Carner, hi sobresurten dues obres, amarades ambdues d'espiritualitat: d'una banda, el poema llarg en deu cants i de I.365 versos, el Nabi, poema inspirat en l'episodi bíblic de Jonàs. ${ }^{2} \mathrm{D}$ 'altra banda, una colllecció de trenta-un poemes, editats en l'edició de 1957 sota el títol de Verb, que tenen la particularitat de ser, tots ells, poemes, o bé d'inspiració bíblica, o bé de tradició cristiana litúrgica i cúltica. ${ }^{3}$ Aquí, doncs, em centro en el comentari d'un recull de poesies, recopilades en l'edició completa de Poesia l'any i957 sota el títol de Verb, la major part de les quals no havien estat encara publicades en cap llibre de poesia, sinó que, o bé havien romàs inèdites fins llavors, o bé s'havien publicat individualment en algun diari o revista. ${ }^{4} \mathrm{El}$ motiu d'aquesta tria és clar: oferir al lector un comentari sobre la influència veterotestamentària en els versos del poeta: la colllecció Verb, juntament amb Nabí, són les dues composicions poètiques de Carner que es poden titllar de parabíbliques, en el sentit que 
s'emmirallen en els llibres de la Bíblia i els reescriuen, anant més enllà del text antic.

Les obres que giren entorn de la vida i l'obra de Josep Carner són molt nombroses.5 Quant als estudis valoratius de la seva obra poètica, emperò, caldria subratllar la manca d'estudis especialitzats sobre el recull de versos que, per primer cop, aparegueren en l'edició de l'any 1957, quan es publicà la seva obra poètica completa. ${ }^{6}$

Filant més prim encara, les eines bibliogràfiques de què m'he pogut servir a l'hora de fer l'estudi d'aquests poemes escollits dins de la collecció Verb són gairebé inexistents. A mesura que anava recopilant la bibliografia, m'adonava de l'existència d'estudis que valoraven llibres de poesia concrets, publicats a part, abans de l'edició del I957 -és el cas, per exemple, de llibres com Els fruits saborosos o Nabí, entre d'altres-i que eren, sovint, tractats per més d'un estudiós. ${ }^{7}$

En el cas de la collecció que ens ocupa, emperò, només he pogut trobar un article que estudiï mínimament el tema que ens interessa: és l'article de Schreiber (1992), un estudi global, encara que no exhaustiu, de les poesies recollides en Verb.

El recull de poemes que es troben en Verb és format pels següents trentaun poemes de tradició bíblica veterotestamentària i cristiana (veg. Carner, Obres Completes 968-969 i Schreiber 285-286):

I. Cants de Caïm i d'Abel; 2. Cants de Raquel (NPL); 3. L'Eternal i el temple; 4. Cant del just; 5 . Salm de la captivitat (NPL); 6. Cançó d'esperança; 7. L'esperitat (NPL); 8. L'espera dels patriarques (JFB); 9. Els patriarques (Cor); IO. Els profetes (Cor); I I. Els màrtirs (Cor); г 2. Els doctors (Cor); I 3 . Els confessors (Cor); I 4. Les verges (Cor); I s. Les vídues (Cor); I6. El pecador (OrC); 17. Estels (OrC); I 8. Invitació de febrer (CoQ); i 9. Dimecres Cendra (CoQ); 20. Quaresma (CoQ); 2 I. Divendres Sant (CoQ); 22. Nocturn (CoQ); 23. Mare entre cims; 24. Perdut en mon jardí (CoQ); 25. Proximitat de la mort (CoQ); 26. Temptació (Mon); 27. Capvespre de juny (CoQ); 28. Pregària d'infant (NPL); 29. Any nou (NPL); 30. Si us plau (NPL); 3 I. Prec de la darreria (NPL).

La selecció dels títols, doncs, mostra que Carner s'inspirà no tan sols en la Bíblia, ans també en el transcurs de l’any litúrgic. Juntament amb Nabi (194I), que el mateix Carner considerà la seva obra més notable (Porcel 949-957), aquest recull de poemes es caracteritzen per descriure i adaptar argumentalment i parafràstica algun dels passatges de l'Antic Testament. Des del punt de vista del corpus carnerià, són, doncs, versos "parabíblics”, tal com ja s'ha comentat, en el sentit que reescriuen algun passatge de l'Antic Testament $i$ van més enllà d'aquest, car sovint s'adapten a la vida $i$ al moment històric del poeta.

Els poemes que configuren el recull poètic de Verb segueixen un ordre generalment cronològic. El ventall s'estén des dels principis de la història de la Salvació en l'Antic Testament i el seu acompliment al Nou (fets reflectits en el transcurs de l'any eclesiàstic i de les seves festes) fins a l'oració retrospectiva del poema final "Prec de la darreria" (Schreiber 287). 
Cenyint-me a raons bàsicament temàtiques, com que l'objectiu de l'article és resseguir la petja de l'Antic Testament en aquests versos carnerians, he decidit d'escollir, d'entre la collecció de trenta-un poemes, només aquelles poesies que tenen una clara inspiració en la Bíblia Hebrea. Així, en aquest article, s'hi analitzaran literàriament els poemes següents: "Cants de Caïm i d'Abel", "Cants de Raquel”, "L’Eternal i el temple", "Cant del just”, "Salm de la captivitat", "L'espera dels patriarques", "Els patriarques" i "Els profetes". La resta de composicions poètiques queden fora d'aquesta tria, perquè fan referència a episodis i personatges neotestamentaris.

El comentari de cadascun d'aquests poemes serà formal i estilístic, però sobretot anirà encarat a la cerca de la petja bíblica i a l'anàlisi del tractament subjectiu o objectiu de la font bíblica feta pel poeta.

\section{Les fonts bíbliques en CARner: Comentari literari DE VUIT POEMES DE LA COL·LECCIÓ VERB}

\section{I. "Cants de Caïm i d'Abel"}

\section{I}

Aquest és el cant de Caïm:

Vull ésser tot sol en el cim.

Si por de mon nom en prové, el mal que jo faig és mon bé.

Sentiu la tonada
d'Abel:
Vaig enfora, menant l'ovellada,
polseguera humil sota el cel.
I faré, de retorn, conversada
amb Qui mena al gran prat cada estel.

Quan l'any 1957 apareix l'obra poètica completa, aquest poema era encara inèdit, no recopilat en cap dels reculls poètics de Carner. En aquest poema, s'hi rememora la història bíblica de Caín i d'Abel, coneguda pel passatge de Gn. 4, I-I6.9 L'acció del poema se situa en els moments previs al fratricidi (Gn. 4, I-7).

En la primera estrofa, formada per un quartet de rima parallela, del tipus $a a b b$, de versos octosíllabs, rima masculina i consonant, la veu cantant és la de Caín; el pagès mostra la clara intenció del germà fratricida: l'orgull, el gaudi personal de fer el mal i l'egoisme hi són clarament manifestats: Carner construí l'estrofa amb versos de rima masculina, rima molt més contundent a efectes de dicció. ${ }^{\circ}$

Aquesta primera part es troba, doncs, sota el signe de la supèrbia de la rebelllió de Caín. La força del mal, que ha trobat accés a la humanitat a causa 
del pecat dels primers pares $(\mathrm{Gn} .3$, 5) s'expressa també pel pensament de Caín: “-Vull ésser tot sol en el cim”. L'ànim egoista i violent de Caín es veurà contraposat per la segona estrofa, on s'hi subratlla l'esperit pacífic, bo i humil d'Abel.

La paradoxa del darrer vers de la primera estrofa, que podria sonar cínicament referida a la persona de Caín, queda suprimida tenint en compte aspectes de la història de la Salvació: del crim atroç de Caín, en neix el bé, ja que el sacrifici d'Abel, que per la seva mort esdevé anyell ofert en holocaust, fou considerat, a partir de l'època constantiniana, com a prefiguració de la mort de Crist a la creu (Schreiber 305).

En la segona estrofa —encapçalada per un dístic pentasílllab i bisílllab i seguida per un quartet de rima consonant encadenada (cece), el primer i tercer vers del qual té rima femenina i el segon i el quart, masculina-, ja s'hi empra una rima alternada, que barreja la rima masculina, forta i greu, amb la femenina, més lleugera que la rima de mots aguts.

Llevat del fet que Abel fos pastor, no s'hi fa cap referència a la història de la parella bíblica de germans. Abel hi declara el seu desig: després de portar el ramat a pasturar, vol fer una ofrena a Déu (vv. 9-Io). S'estableix en el quartet d'aquesta segona estrofa una bella imatge metafòrica entre Abel, senzill pastor de ramat, i Déu, el gran pastor de l'estelada en el cel.

En aquesta segona estrofa, tal i com subratlla Schreiber (305), pot establir-se una similitud entre la figura d'Abel i la de Crist: Abel, com a pastor, és la prefiguració de Crist, del Bon Pastor, que dóna la vida per les seves ovelles (Jn. Io, I I). ${ }^{\text {II }}$

Ambdues estrofes, doncs, es contraposen, per mètrica i per sentit, quant a la intenció de cadascun dels germans: $:^{12}$ la primera és rellevant quant a la voluntat superba de Caín, el fill primogènit i fratricida. La segona, ja no es tan dura en paraules, $i$ les imatges $i$ metàfores que s'hi descriuen, traspuen la bondat d'Abel, el pastor, la fe del qual envers Déu es mostra infinita.

\section{2. "Cant de Raquel”}

Raquel era de bella cara $i$ cos. -Gn. 29, 17

I Sigues lloat, oh Déu, oh pròdig en bellesa, perquè el meu cos vas tornejar tan fi que gota de rosada o serení el seguiria tot, sense restar-ne presa.

s Oh Tu que has fet la fulla perfecta en un sol dia $i$ en dos milers d'anyades el blau palet oval, que fins al temps de noces que el teu voler em destria, d'amor ni de desig no prengui mal! 
Mon cos — demà l'espargiràs en cendraIo avui, perquè t'hi plaguis en ton edem soliu, dansa com una flama que es dóna i es desdiu, o ja, pensós, es tanca, com el plançó més tendre.

Tu em lliuraràs — i te'n seré pagada-, a qui ja saps: al cor que per a mi prevens.

Is Tingues-me fort, que espero la resplendent diada com dins un castell emmurada.

I senten mos ulls baixos que els d'altri són ardents.

Mena'm qui Tu voldràs, quan sigui l'hora.

Però decanta't a donar-me aquest senyal:

20 que de la treballada se'm mostri al termenal, $\mathrm{i}$ amb els pastors de casa, del nostre pou devora, bellugui la gran mola damunt la deu pairal.

De cara al sol ponent de legions vermelles, jo, davallant pel caminal estret,

25 li semblaré guarnida de roses en esplet;

servirà l'aigua a les meves ovelles

i jo en prendré una embosta per a la meva set.

I, a llum de lluna —a penes un fil - que prop de l'eixida hom vegi una ombra sola de tots dos,

$30 \mathrm{i}$ un desesment em faci defallida

i caigui el meu castell imperiós.

Del primer bes seré per sempre segellada.

Tu no m’has fet, jo no só nada per a un amor que es deixi consumir.

35 Captiva com pertoca, sotmesa i entestada, mon príncep serà meu fins a morir.

Que sigui meu. ¿Què em fa, si Tu l'emmenes en visió perdut o pres d'un pensament?

$\mathrm{Al}$ seu retorn el nuaran mes trenes:

40 el meu lligam, que amb ton lligam s'entén.

Que sigui meu. ¿Què em fa si parla amb folles drudes, què em $\mathrm{fa}$, inestable, d'altres dones la remor?

$¿$ Que ell tingui, com villatges, amors inconegudes

si só la seva nació?

45 I ara, Senyor del Cel, que ens ames i amonestes...

Dona em creares en feixuga llar

i só pastora del meu pare avar.

Però mon cor té rufagades $\mathrm{i}$ tempestes

com dins una curculla hi ha la mar. 
50 Què en farà mai del seu orgull la trista dona?

M'eixuga, em fibla amb el seu dur batec.

Per a les falconades d'amor seré prou bona?

Caldrà que al fill acosti un pit ressec?

Però si tu em volies eixorca i vilipesa,

55 ¿per què de dos orgulls m’obligues al fatic,

amb la meva bellesa i la promesa

que feres a Abraham, el teu amic?

Dóna'm a mi la sort que escaigui, però val-me en mon afany: puc terrejar pacientment

60 si un fill hereta el meu callat turment

i se li torna honor en un reialme:

rei, o bé, prop del rei, omnipotent.

No pas un lloc d'Entre-dos-rius escolliria

per al seu gran renom

65 (ací tot són revoltes i allaus d'estrangeria.

Sovint és lluny o trossejat tothom),

sinó una terra en arts de pau entesa,

on vivents $i$ finats rebin conhort

d'un riu que tot ho negui de riquesa,

70 de monuments que us diguin que han aterrat la mort.

Amb aquest poema, Carner va guanyar l'any 1947 una Viola als Jocs Florals de Londres, però trigaria encara deu anys en aparèixer publicat en llibre, dins el recull de Verb, amb motiu de la publicació, l'any 1957, de l'obra poètica completa del nostre autor.

Aquest llarg poema de setanta versos és format per setze estrofes: deu quartets i sis quintets. És un cant de prec i de lloança que fa Raquel a Déu, en acció de gràcies. La primera persona, estil directe que evoca la pregària feta per Raquel, alterna amb els imperatius i subjuntius cupitius de segona persona, amb vocatius inclosos, adreçats a Déu.

El gènere d'aquesta composició és difícil de definir. Schreiber (3 I4) és de l'opinió que els elements realistes, visionaris i al-legòrics que s'hi troben es barregen per formar una unitat que es pot qualificar de càntic amb elements èpics. El poeta fa cantar Raquel en persona i la presenta en un cant visionari: l'himne el canta una pastora, encara fadrina i no pas, com opina Cardona ("Ell i el poeta", I68), "una dona plena de recances, desenganyada en la senectut $i$ queixosa".

Amb relació a la mètrica, les estrofes alternen entre quartets (I, II, III, VII, IX, $\mathrm{X}, \mathrm{XII}, \mathrm{XIII}, \mathrm{XV}, \mathrm{XVI}) \mathrm{i}$ quintets (estrofes restants). La rima, consonant i alternada (masculina i femenina), a voltes és creuada (ABBA), a voltes encadenada (ABAB). Els versos més nombrosos són els decasíllabs combinats amb els alexandrins. 
Carner hi empra també, més esporàdicament, versos d'art menor (un hexasíllab, v. 64, i tres octosíllabs, vv. I6, 33, 44).

Cal situar aquest càntic de lloança just abans de l'episodi narrat al llibre del Gènesi (29, I-30), on es descriu la coneixença entre Jacob i Raquel —filla de Laban, ${ }^{13}$ oncle de Jacob- mentre abeuren les ovelles, i el casament posterior de Jacob amb Lia i Raquel.

S'encapçala el poema amb un versicle extret del Gènesi $(29,17)$, que fa referència a la bellesa de Raquel. El càntic s'adreça a Déu: en el poema, doncs, s'hi alterna la primera persona, que fa referència a Raquel, amb els imperatius i subjuntius dessideratius adreçats al Senyor. Hi són presents, per tant, els vocatius que fan referència a la divinitat i els epítets: ob Déu, ob pròdig en bellesa (v. I), ob Tu (v. 5), Senyor del cel (v.45). ${ }^{\mathrm{I}}$

Les quatre primeres estrofes són útils per situar el lector en el poema: Raquel dóna gràcies al Senyor per haver-li donat bellesa (primera estrofa) i hi expressa el prec de no prendre mal d'amor (estrofes II, III i IV).

La cinquena i sisena estrofa ja ens situen en un marc de clara ressonància bíblica: Carner, plenament omniscient dels esdeveniments bíblics, fa que Raquel demani un senyal de Déu per a conèixer qui ha de ser el seu promès. De manera parafràstica, doncs, Carner relata en vers el que s'esdevé en Gn. 29, I0: "Quan Jacob va veure Raquel, la filla del seu oncle Laban, amb el ramat d'aquest, anà a la boca del pou, féu rodolar la pedra que el tancava i va abeurar el ramat del seu oncle Laban".

Les estrofes viI, viII, IX i x fan referència a la voluntat de Raquel -i a la vegada, la de Déu: l'amor envers Jacob ha de durar per sempre: "del primer bes seré per sempre segellada" (v. 32), "mon príncep serà meu fins a morir" (v. 36), "que sigui meu" (primer hemistiqui, v. 37 i v. 4 I).

En l'onzena estrofa, es fa referència a l'ofici de Raquel, que era pastora de les ovelles del seu pare Laban (així també a Gn. 29, 9), el qual és titllat “d'avar” en el vers quaranta-set, segurament pel fet d'haver fet treballar set anys el seu nebot Jacob, no haver complert la promesa de cedir-li Raquel en matrimoni, i obligar-lo a treballar durant set anys més, per poder maridar-se amb Raquel (Gn. 29, 2 I-30).

En el darrer vers de l'estrofa dotzena i en la tretzena, s'hi rememora l'esterilitat de Raquel (cf. Gn. 29, 3I), fet que topa amb la paradoxa de la seva bellesa i amb la contraposició de la promesa que Déu féu a Abraham (Gn. I7, 5-6). ${ }^{\text {Is }}$

En l'estrofa catorzena, Raquel s'encomana a Déu i li demana de rebre un fat que li escaigui (v. 57). S'hi fa referència, també, al seu fill primogènit, Josep, qui, llançat al pou i venut com a esclau a Egipte pels seus germans, finalment és nomenat ministre de tot aquell país pel Faraó: aquí, Raquel acceptarà el seu destí a canvi que el seu fill sigui honorat en un gran reialme, vora un rei omnipotent (vv. 60-62). ${ }^{16}$ És, doncs, una clara referència a la història de Josep a Egipte i la relació establerta amb el faraó, en qualitat de primer ministre, narrada al llibre de Gènesi (39-45).

S'acaba el càntic de Raquel amb dos quartets al-legòrics: Raquel, jugant amb el coneixement que té Carner del passatge bíblic, que el reialme escollit per al 
seu fill no sigui Mesopotàmia ("no pas un lloc d'Entre-dos-rius escolliria/ per al seu gran renom vv. 63-64), ans la terra d'Egipte, una "terra en arts de pau entesa", una terra "d'un riu que tot ho negui de riquesa, de monuments que us diguin que han aterrat la mort" (vv. 67, 69 i 70).

\section{3. "L'Eternal i el temple"}

I Salem, la dels misteris i els martiris, entrar veié dins de son clos potent, al so de corns, de címbals i saltiris, l'arca del Déu vivent.

5 -Tremi de goig el cel, canti la terra, soni la mar i tot indret boscà; i que la mel de la bolcada gerra conhorti el dol humà.

Senyor del cel, que amb els teus fills descanses, Io del front irat apaivagant el solc: entorn del pavelló, que tes lloances entoni tot el folc.-

I féu David: -Oh raça malastruga! avarament servírem l'Eternal.

Is ¿Per què un sostre de cedre m'aixopluga $i$ a l'arca un sol tendal?

¿Què són corona, ceptre i senyoria davant de l'Eternal que em beneí? Segellaré el meu cap que s'humilia $20 \mathrm{amb}$ pols del meu camí.

Pel cisell i el ribot deixo l'espasa, deixo la festa pel martell i els claus. Déu Eternal, jo et bastiré una casa més bella que els palaus.-

25 Déu a David, el fill de sa clemència, fermà de sobte la paraula, el peu. I la nit s'arborà d'una presència $\mathrm{i}$, sense llavis, ressonà una veu:

- Jo t'he fet rei, d'escadusser poeta 30 que fores entre ovelles d'un ramat; t'he salvat de la llança i la sageta i l'urc de Goliat. 
T'he ventallat el cor com una palma, t'he alçat el front i t'he colrat la pell, 35 t'he lliurat l'enemic de ton reialme $i$ el meu poble t'he dat com a escambell.

Vencé ton braç, ardit de ma guspira; munts d'horror m'oferires, benastruc: la ira en el combat és pitjor ira 40 quan mon nom repeteix en son ahuc.

Emmetzina el poder, cega la glòria. És a un fondal que la furor empeny; us fa vils l'endemà de la victòria. Qui mai al món destriarà el meu seny?

45 Jo prenc qui vull per a ma eterna pleta; si a un rei per al triomf he dat virtut, sovint entre els estels, amb la mà dreta honoraré el vençut.

El vostre fang, la vostra sang impura so es donen en la lluita a un foll esplai; són fets del vostre cor a la mesura mos atuells d'esglai.

Sota d'una arca humil i reverenda, Jo, que ningú no veu de fit a fit, 55 he anat de lloc en lloc, de tenda en tenda, escàpol amb mon poble perseguit.

Trist de qui cau en la batalla irada, i més qui el féu abatre's i sagnar. D'un pobre cor manyac em faig estada, 60 d'un esbarzer que crema em faig altar.

Tindràs un fill, de saviesa exemple, de cor benigne i manament suau; serenament, ell alçarà mon temple com monument de pau.

65 De fer-ho tu, debades em demanes, cobert, per una estona, de lli blanc: no bastiran mon temple mans humanes que han espargit la sang.

Aquests disset quartets són una recreació poètica i personal del passatge narrat en el segon llibre de Samuel (cap. 6-7), on s'hi descriu el trasllat de l'arca de l'Aliança a Jerusalem, el pla de construcció del temple ideat per David i el rebuig de la idea per part de Jahvè. Carner sintetitza l'episodi bíblic i en supri- 
meix passatges i personatges circumdants: la profecia de Natan (2Sa. 7), per exemple, en els versos de Carner apareix com a revelació divina feta directament a David, sense la intervenció de cap profeta.

Quant a la mètrica, el poema és format per disset quartets de rima encadenada (tipus ABAB), consonant $i$ alternada (masculina i femenina). Els quartets VII, IX, X, XI, XIV, XV són formats per versos decasílllabs. La resta d'estrofes tenen els tres primers versos dels quartets formats per decasíllabs, mentre que el darrer és un hexasíllab, que sol rimar amb rima masculina amb el segon vers del quartet.

Estructuralment, el poema es pot dividir en tres parts. La primera (estrofes I-III) relata l'entrada triomfal, acompanyada de música i dansa, de l'arca de l'aliança a Jerusalem (vv. I-4) i el càntic de lloança i de joia que entona el poble de Jerusalem - i d'Israel en general segons la Biblia Hebrea- (vv. 5-I 2). Jerusalem és citada amb l'epítet de Salem, la ciutat reial de Melquisedec (Gn. I 4, I 8), visitada per Abram (Gn. I 4, I 8 i He 7, I): aquesta ciutat és generalment identificada amb Jerusalem (veg. el parallelisme amb Sió en el Salm 76, 3). Aquesta primera part ens remet al passatge bíblic del segon llibre de Samuel, capítol sisè, on es fa referència al trasllat de l'arca a Jerusalem.

El primer vers del tercer quartet ("Senyor del cel, que amb els teus fills descanses" v. 9) és un vocatiu adreçat a Déu i té un clar paralllelisme amb $2 \mathrm{Sa}$. 6, 2b: "l'arca de Déu, que porta el nom del Senyor, Déu de l'univers, el qui té per tron els querubins”. Prenent, doncs, aquest parallelisme, hom entén que els querubins són els fills amb qui descansa Déu. ${ }^{17}$

La segona part del poema comprèn les estrofes IV, v i vi, en què s'hi recreen, en estil directe i en boca del rei David, les paraules que el rei adreça, en el passatge bíblic, al profeta Natan $(2 \mathrm{Sa} .7,2)$ : "El rei va dir al profeta Natan: -Mira, jo visc en un palau de cedre, mentre que l'arca de Déu habita en una tenda de lona" (cf. vv. is i i6). En l'estrofa sisena, doncs, i abans de l'aparició de la veu divina, David té la intenció de bastir un temple al Senyor.

La tercera part, i la darrera, és formada per les estrofes restants (VII-XVII); aquí s'hi exposa, en primera persona, el parlament de Déu dirigit directament al rei David durant la nit (vv. 25-28), que li rememora el seu passat bellicós (vv. 29-52), la seva situació de culte itinerant i senzill (vv. 53-60) i la voluntat, a manera d'oracle i d'auguri, que sigui el seu fill Salomó, "de saviesa exemple, de cor benigne i manament suau", el bastidor del temple, i no pas ell (vv. 6I-68).

Amb un quartet, l'estrofa setena relata la "fonofania" divina al rei David. En aquesta estrofa, Déu fa sentir la seva veu directament al rei, la qual cosa s'esdevé de manera diferent en el passatge bíblic, on el Senyor s'apareix al profeta Natan, perquè li comuniqui unes paraules a David (cf. 2Sa. 7, 4-6).

En la vuitena estrofa, Déu rememora a David el seu passat humil i els prodigis que el Senyor ha fet per ell. El passat del rei, com a pastor i com a poeta músic, es pot resseguir a iSa. I6, I 9 i ISa. I6, I 8 respectivament, entre d'altres passatges. La història de la lluita amb Goliat, a què fa referència el vers 32, es pot seguir també en ISa. I7, I-54. L'exposició dels versos també recorda les paraules que Déu adreça a Natan (2Sa. 7, 8b): “Jo t’he pres del 
clos de les ovelles, de pasturar el ramat, perquè fossis sobirà del meu poble d'Israel".

L'estrofa novena i desena fan referència a les guerres i victòries del rei $\mathrm{Da}$ vid, descrites en el primer llibre de Samuel i en l'inici del segon, i la reialesa de David (2Sa. 2). Aquesta estrofa recorda les paraules que Déu adreça al profeta Natan a 2Sa. 7, 9: "He estat amb tu en totes les campanyes que has emprès, he derrotat els teus enemics i t'he donat una anomenada com la dels homes més famosos de la terra".

Les tres estrofes que segueixen (XI, XII i XIII) fan referència al poder que té de corrompre la victòria, la glòria i el poder. Aquestes tres estrofes es contraposen amb les dues que segueixen a continuació (xIV i Xv), on s'hi exposa la situació d'humilitat i senzillesa amb què els israelites han tractat el seu Déu: "Sota d'una arca humil i reverenda,/ Jo, que ningú no veu de fit a fit,/ he anat de lloc en lloc, de tenda en tenda,/ escàpol amb mon poble perseguit" (vv. 53-56). Aquests versos evoquen també les paraules de Déu adreçades al profeta Natan ( 2 Sa. 6-7): "D'ençà del dia que vaig treure els israelites d'Egipte fins ara, no he residit mai en cap palau; anava d'un lloc a l'altre en una tenda, en un tabernacle".

El poema s'acaba amb dos quartets que declaren la voluntat de Déu que sigui Salomó el bastidor del temple i no pas ell, David, car té ja les mans massa impures de sang. Ambdues estrofes són escrites amb un to d'auguri per a la posteritat: formalment s'hi empren, doncs, futurs com a temps verbals ("tindràs", "alçarà", "no bastiran”). Aquestes dues estrofes reprodueixen fidelment el passatge bíblic de $2 \mathrm{Sa}$. 7 , I 2-I 3 en què Déu transmet a Natan les paraules que ha de comunicar a David.

\section{4. "Cant del Just"}

I No passaré mai pena, que l'Eternal em guia per senderons que solquen les gespes verdejants, $i$ em $\mathrm{fa}$ anar vora l'aigua que no sona

i a l'hora del capvespre m'ungeix amb el descans.

5 En obeint-lo, sento son braç, que mai no pesa;

quan caic, en oblidant-lo, em cull com un amic; i em diu: -T'he dat un signe en l'iris sobre el núvol—, i fa que aroma llevi tot el meu dol antic.

Delit de cosa vana, tot el que es mou i dringa.

I० I quietud que torna la pietat del cel; fins en estranya terra i en casa esvorancada ha proveït mos dies de l'oli i de la mel.

Ni per la vall obaga d'extrema darreria si l'Eternal em mena no temeré la fi;

is el ventijol, la fulla murmuren sa lloança, son bàcul em conforta, son pas m’obre camí. 
Ploreu, sobretot, pels qui viuen.

Només que uns passos i una pols la fi consum.

La fossa no pren més que una despulla, 20 i part d'allà de l'ombra viu immortal la llum.

Aquest poema té l'estructura pròpia d'un salm bíblic de pregària. S’hi ressegueixen clars paralllelismes, per contingut, amb el Salm 23, "El Senyor és el meu pastor", construït amb quatre estrofes de clàssica estructura paral-lelística, recurs propi, per altra banda, de la poesia hebrea, que funciona en dístics mitjançant el recurs sintàctic del parallelismus membrorum. ${ }^{18}$ Sobretot les estrofes primera i quarta es componen, en gran part, de fragments d'aquest Salm; en aquest poema, Carner domina la dicció bíblica tant perfectament, que els límits entre cita, reminiscència i alllusió gairebé es desdibuixen.

Aquest és un poema en cinc quartets de rima consonant $\mathrm{i}$ alternada, del tipus АВСВ: només rimen, amb rima masculina, el segon i quart vers de cada estrofa. El primer i tercer vers de cada quartet presenta sempre una rima femenina. Tal i com fa notar Schreiber (295), no són pas quartets, el que tenim aquí, ans - a la manera dels romanços — dístics apariats en versos llargs, com en la poesia hebrea dels salms.

Les quatre primeres estrofes presenten versos alexandrins amb cesura de rima femenina en la sisena síllaba. La darrera estrofa manté la rima tipus $\mathrm{ABCB}$ (LMNM), però amb la particularitat de la variació de vers: el vers i 8 i 20 són alexandrins, mentre que el vers i 7 és un octosílllab i el vers i 9 un decasílllab francès amb la cesura sintàctica en la sisena síllaba. L'absència de rima final, per una banda, i de versificació isosillàbica, per l'altra, característiques inherents, ambdues, de la poesia romànica, recorden l'estructura formal de la poesia hebrea bíblica.

El poema es pot estructurar en dues parts: la primera (estrofes I-IV) és construïda prenent com a base l'estructura pròpia d'un salm de pregària: són aquestes estrofes les que guarden un lligam molt estret amb el Salm 23 (en especial, la primera i la quarta). S'hi troben, també, altres ecos literaris del llibre de Qohèlet (I, 2) i de Virgili (Eneida VI, v. 679 i vv. 703-705).

La segona part, l'estrofa darrera, es desmarca de les altres pel seu to imperatiu i asseveratiu i per la creença en la immortalitat de l'ànima, a diferència del cos físic, més enllà de la mort (v. 20): és un quartet, el darrer vers del qual ultrapassa la visió existencialista de Qohèlet, i referma la creença en la immortalitat.

El primer quartet expressa la fe $i$ la confiança en el Senyor, entès com a pastor-guia del jo líric. Aquesta estrofa traspua un clar rerafons bíblic, car s'equipara amb la primera estrofa del Salm 23: "El Senyor és el meu pastor:/ no em manca res./ Em fa descansar en prats deliciosos,/ em mena al repòs vora l'aigua,/ i allí em retorna”.

A part de la influència bíblica, el segon vers d'aquesta primera estrofa té ressò llatinitzant i recorda el passatge virgilià de l'Eneida (VI, v. 679 i vv. 703-705).

La segona estrofa (vv. 5-8) presenta un parallelisme clar amb el salm mencionat. Hi destaquen tres factors interessants: el primer, l'ús lingüístic, de re- 
gust molt literari i arcaïtzant (llatinitzant), de la preposició “en” seguida de gerundi, reproduïda dos cops, a manera de parallellisme, en els versos 5 i 6 ("en obeint-lo", "en oblidant-lo").

El segon, la referència a la paraula "braç" (v. 5), un mot carregat de simbolisme: a l'Antic Testament, el braç i la mà són el signe del poder providencial, salvador o punitiu (cf. Ex. 6, 6; Dt. 5, I6; 2Sa. 24, I 5; Sl. 21, 9; 32, 4; Is. 30, 30). L'expressió carneriana "son braç que mai no pesa” evoca passatges del Nou Testament (veg. Mt. I I, 28-30i també IJn. 5, 3).

El tercer, la referència a l'arc de Sant Martí (v. 7) com a signe diví. En general, i en termes mitològics, l'arc de Sant Martí és el símbol que fa de pont entre el cel i la terra; expressa, sempre i en tot lloc, unió, relació i intercanvi entre ambdós indrets. En la tradició bíblica, apareix com a signe d'apaivagament de l'ira divina, de conclusió d'una nova aliança, protegida per la benvolença divina (cf. Gn. 9, I 2-17). ${ }^{19}$

Quant a la tercera estrofa, sembla estar estretament lligada amb la cinquena: ambdues estrofes s'allunyen una mica del sentit global del poema (Schreiber 298). Es comentarà més endavant, doncs, en parlar de la cinquena.

La quarta estrofa, com ja s'ha subratllat, s'inspira clarament amb el Salm 23, talment demostra la confrontació següent:

Ni per la vall obaga d'extrema darreria si l'Eternal em mena no temeré la fi; el ventijol, la fulla murmuren sa lloança, son bàcul em conforta, son pas m’obre camí.

(vv. I3-16)
Ni que passi per la vall tenebrosa no tinc por de cap mal.

Tu ets vora meu:

la teva vara i el teu bastó

em donen confiança. (Sl. 23, 4)

Les estrofes tercera i quinta, com ja hem comentat, es veuen molt lligades entre sí. La cinquena estrofa és l'expressió màxima de la fe cristiana (veg. M. Manent 35). El vers I7 sembla contenir una reminiscència verbal de la història de la passió (Lc. 23, 28), on Jesús, camí del Calvari, consola les dones que ploren. El prec de no plorar pel moribund, sinó pels vivents, pren clarividència només a partir dels dos versos següents i darrers: la mort del cos físic permet l'accés a la vida eterna, illuminada, moment d'esperança i alliberament per a la fe cristiana (Schreiber 298). ${ }^{20}$

L'estrofa tercera esdevé també clara, en relacionar-se amb la darrera: si la vida terrena sub specie aeternitatis és només "delit de cosa vana", llavors, cal plànyer els vius pels seus inquiets neguits: tan sols en Déu troben el repòs després de la inquietud mundana (Schreiber 299). El vers 9 recorda l'escèptic llibre del Cohèlet $\mathrm{i}$ el tema central del llibre: "vanitas vanitatis, diu Cohèlet, tot és efímer, tot és en va” (Coh. I, 2). Però l'escepticisme d'aquest llibre es veu esborrat pel vers Io, amb l'esperança de la vida eterna i la conseqüent "quietud que torna la pietat del cel” i, finalment, pel darrer vers del poema: "i part d'allà de l'ombra viu immortal la llum". 
Talment com subratlla Schreiber (299), els versos i I i I 2 criden l'atenció pel regust bíblic que tenen, tot i que no s'hi detecti cap paraula presa directament de l'escriptura. Malgrat tot, "estranya terra i casa esvorancada" — tot i que, pel que sembla, facin esment a l'exili, a l'emigració i a l'opressió de la pàtria catalana - imatges de la situació transitòria de l'existència terrenal, fan pensar un altre cop en Sant Pau (2Co. 5, I-6), mentre que "oli" i "mel” evoquen la Terra Promesa, cap a la qual camina el poble escollit.

\section{5. "Salm de la captivitat"}

I Cada mirada nostra és entelada;

cada mot nostre, esclau.

Cada dia atueix les nostres vides

qui ens mena amb jou per odi de la pau.

5 Oh Déu que ens assabentes amb el càstig!

Que el so del nostre plany et sigui dolç.

Els teus servents amen llurs pedres

i es compadeixen de llur trista pols.

Refés els nostres dies amb saba d'esperança;

IO cruel és tot poder si ton esguard en fuig;

que et resti obedient qui se't confia:

serà desfet qui es deia armat pel teu enuig.

Tu que, excelllint en pietat els jutges, salves d'una mirada el condemnat,

Is redreça la desferra del que fórem,

dóna’ns penyora de benignitat.

El temps de prova dura una diada, ton càstig una nit.

Mai no serà tot temps sotraguejada

20 la terra que has bastit.

Soni la nostra veu, que ara ens ofeguen, en càntic immortal.

Salva, a l'abric de renaixents columnes, el nostre clos pairal.

25 I que l'or de la teva solellada consoli les afraus, coroni el cim quan ton alè ens retiris $i$ encara ens facis terra d'aquella d'on venim.

Aquest poema romangué inèdit fins l'any 1957, any en què aparegué publicat en l'obra completa, dins el recull de Verb. Aquests versos foren escrits en temps de 
postguerra, moment en què Carner "assumeix la condició de poeta al servei de Catalunya" (Santaeulàlia 34I). Carner no parla, en els versos patriòtics que escriu en aquest moment històric, com a simple espectador del món, ans com a membre d'una collectivitat, per a la qual assumeix, de vegades, el deure de guiar-la. La poesia, aleshores, esdevé un instrument de mitificació de la identitat nacional, d'expressió d'inquietuds i esperances sobre el destí de la comunitat i es caracteritza pel seu to nostàlgic, elegíac de l'home cansat i vençut que, malgrat tot, s'obstina a proclamar la seva fidelitat al "tros nadiu” i l'esperança en un futur més clar.

L'estructura i el to del poema recorda un salm bíblic de lamentació. El contingut d'aquest salm carnerià evoca la lamentació present en el Salm I 37 ("Vora els rius de Babilònia"), un salm paradigmàtic, quant a l'enyorança de Sió, que senten els jueus exiliats a Babilònia. Podria veure's, doncs, aquest salm com a pregària de lamentació per la situació actual del país (vv. I-8) i un prec de súplica esperançadora de cara a l'esdevenidor de la terra catalana (versos restants). És, doncs, un salm patriòtic i, alhora, elegíac, però amb esperança ("soni la nostra veu, que ara ens ofeguen,/ en càntic immortal./ Salva, a l'abric de renaixents columnes,/ el nostre clos pairal”).

Quant a la mètrica, és una poesia de vint-i-vuit versos, estructurada en set quartets de rima consonant $\mathrm{i}$ alternada (del tipus $\mathrm{ABCB}$ ) on només rimen, amb rima masculina, el segon i el quart vers de cada estrofa. El poema combina versos decasílllabs i alexandrins amb versos d'art menor (sis hexasíllabs en els ver$\operatorname{sos} 2, \mathrm{I} 8,20,22,24,27)$ i un d'octosíllab, amb rima masculina, en el vers setè.

El salm es pot dividir en quatre parts. La primera, que correspondria a la primera estrofa, exposa la situació present del poble català, sotmès a un jou hostil; la imatge del poble abatut i derrotat, i l'allusió a la dictadura franquista és tan clara, que sorprèn que aquest poema passés la censura de l'època (vv. I-4).

La segona part concideix amb la segona estrofa: s'hi fa una crida a Déu (“Oh Déu que ens assabentes amb el càstig!”, v. 5): el poble ja s'ha compadit ("els teus servents amen llurs pedres/ i es compadeixen de llur trista pols”, vv. 7-8), i ara cal tenir compassió d'ell ("que el so del nostre plany et sigui dolç", v. 6), tot i que Déu castigui el poble pel fet d'haver pecat; la dura prova del present, la humiliació, és vista com l'expiació d'aquesta falta.

En la tercera part, que comprendria les estrofes iii, iv, v i vi, s'hi expressa, de manera imperativa i adreçada sempre a Déu, el desig del poble català que el Senyor escolti les seves pregàries: "Refés els nostres dies amb saba d'esperança” (v. 9); "redreça la desferra del que fórem,/ dóna'ns penyora de benignitat" (vv. I 5 I6); "Salva, a l'abric de renaixents columnes,/ el nostre clos pairal” (vv. 23-24).

La darrera part és formada pel darrer quartet, una estrofa de gran força estètica i molt significativa, que barreja pinzellades individuals de transcendència amb traços comunitaris de patriotisme: més enllà de la mort, quan retorni el cos a la pols d'on ha sortit, que sigui el poble recompensat amb la llum eterna del Senyor (vv. 25-28).

Vista la darrera estrofa final, aquest conjunt de versos formen un poema d'esperança patriòtica: de fe en un futur millor per al poble i, en termes escatològics, 
per a cadascun de nosaltres en la vida del més enllà (vv. 25-28). No es tracta, per tant, d'un poema merament d'exili: religió i patriotisme, amb fe i esperança, hi apareixen íntimament relacionats, contràriament a l'opinió d'alguns. ${ }^{21}$

\section{6. "L'espera dels patriarques"}

I Eren onades d'homes, quiets en una espera de més enllà del plany. Passaven les centúries sense petjar la llinda d'aquella pau foscant. Cada cent anys hi anava un nou finat, $i$ en prendre son lloc sentia veus: -No se n'ha esment encara? - I ell ajupia al cap.

5 I tots altra vegada cloïen les parpelles com en un son d'infant; les barbes totes blanques lliscaven com [a] ròssecs d'imarcescible neu; ${ }^{22}$ queien les mans; el bàcul de llur passat viatge restava sobre el pit; d'aquell seguit de boques eixia un sol respir.

I des d'Adam n'hi havia, d'Adam, fill de la terra, fins a sos últims néts; Io immòbils, fets imatges de la més vella cripta, vivien de llur fe.

Si cap sospir sentien, obrien les parpelles i deien lentament:

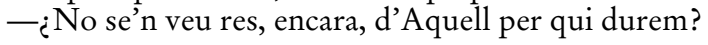

Era una gran carena de cims que coronava no mai petjada neu. Era una gran cadena d'alzines millenàries sense temor del llamp.

Is Era una volta amb llànties, fa temps aparellades, d'or vell i vell argent, tot esperant l'encesa dels dies immortals.

Cada set anys alçaven els braços, sense queixa ni minva de llur pau; cercaven llurs mirades de travessar la fosca, que era llur gran cancell, $i$ es feien llur pregunta, $i$ es feien llur resposta, cada set anys igual: $20-$ No se'n veu res encara? - Tot és encara nit.

Fins que un oreig va trémer; al capdavall de l'ombra hi havia un espirall. I no gosant de creure-hi van dir-se els patriarques: -És un estel perdut-; queien les mans que havien posat damunt les celles per a mirar de lluny $i$ en les parpelles va amagar-se el bri de goig.

25 I l'espirall es feia més gran i s'atansava. Ja flamejava arreu amb llum tota ella pressa. - Així l'Horeb lluïa — clamava Moïsès. I, per la llum batudes, van caure les darreres muralles de la nit i aparegué la cara del Just voltada d'or.

Llença Abraham son glavi i Moïsès les taules, Aaron la vara en flor, 30 Booz la falç pagesa, el rei David la cítara i Job el vil mantell.

Tot rodolà per terra, i trepitjats, els símbols morien sota els peus.

I al crit d'hosanna tots corrien cap al Just.

Del Just en l'abraçada caberen els jerarques i generacions. 
La composició “L'espera dels patriarques”, amb què el Carner de dinou anys va guanyar el I903 la seva primera Viola als Jocs Florals de Barcelona, en aquella primera versió, es titulava "La sacra expectació dels patriarques", i portava, com a lema, el profètic versicle d'Isaïes: "Populus qui ambulabat in tenebris vidit lucem magnam” (Is. 9, 2). Aquest conjunt de versos representen, quant a la forma, un exemplar únic en l'obra carneriana i és, alhora, el poema més antic de tots els que han passat a l'edició completa de 1957.

Cadascun dels versos té una estructura sillàbica regular, tot i que no hi ha cap tipus de rima a final de vers. És format per vuit estrofes de quatre versos i per un vers blanc final. Cada estrofa és un quartet format per tres versos de divuit síllabes; cada vers del quartet, doncs, llevat del darrer que és un dodecasíllab, és integrat per tres hexasílllabs. ${ }^{23}$ La rima dels dos primers hexasílllabs de cada vers és sempre femenina, al contrari del darrer hemistiqui del vers, que té sempre rima masculina. El darrer vers és un alexandrí, el primer hexàmetre dels quals té sempre rima femenina. Entre ells no hi ha cap rima final, i és en aquest sentit que l'estructura mètrica del poema és un xic aliena a les pautes mètriques catalanes $i$, per extensió, a les romàniques: l'absència de rima a final de vers és un tret propi de la poesia semítica antiga i, en especial, de la poesia bíblica hebrea, i de la poesia clàssica greco-llatina, que es regeix per peus mètrics quantitatius, no pas sillàbics.

Aquest poema ens presenta, en immobilitat eterna, els Sants de l'Antic Testament, des d'Adam fins a David, passant per Abraham, Moisès i Aaron (vv. 9 i 29-30): esperen resignadament, com a imatges immòbils (v. Io), l'adveniment del nou messies anunciat (vv. I I-I2). Aquesta espera resignada, doncs, situada en un lloc atemporal i en una cripta aillada de muntanya (vv. I3-I4), és la que s'evoca en la primera part del poema (vv. I-20).

La segona part (vv. 2 I-33), que trenca l'espera de la primera amb la conjunció temporal "fins que", anuncia l'adveniment de Crist, del Just (v. 28), que apareix nimbat d'or, com en una icona. L'arribada del messies és anunciat bíblicament, també, amb l'aparició, d'entre la fosca, d'un "estel perdut" (v. 22), d'un “espirall” (v. 2 I, 25), com s'esdevé en l'Evangeli (Mt. 2, I-I 2). La diferència, emperò, que separa ambdós escrits és que, si bé, en Mateu, l'estrella resseguida pels Mags d'Orient és l'anunciadora del naixement del messies, l'espirall de foc de Carner anuncia als patriarques, a manera d'aparició, l'arribada del Just (v. 28).

El darrer quartet es caracteritza per la comicitat i la plasticitat dels seus versos, pròpies de l'humor fi i irònic de Carner: ${ }^{24}$ amb l'arribada del Just, cada patriarca abandonarà l'atribut amb què és representat en la imatge de la cripta (v. 29-32); així, Abraham, el primer dels patriarques, abandona el glavi, símbol que podria fer referència a l'episodi del sacrifici d'Isaac (Gn. 22). Moisès llança les taules de la Llei, la torà jueva, rebuda directament del Senyor al Sinaí. Aaron, germà de Moisès, i portaveu, es desempallega de la seva vara florida; Booz, el que esdevindrà marit de Rut (Rt. 4), espigoladora de les terres d'aquest, deixa la falç pagesa, l'atribut que el designa posseïdor dels sembrats de blat. El rei David, la cítara, instrument que el caracteritza com a músic, poeta i, a la vegada, pastor; finalment, Job abandona el "vil mantell", imatge que recorda al lector la pobresa i la misèria que 
hagué de patir, fruit dels infortunis que li foren enviats: la pèrdua absoluta dels béns materials i de riqueses (Jb. I, 6-22) i la pèrdua de la salut (Jb. 2, I-IO).

El darrer vers cal que sigui interpretat messiànicament: tots els patriarques, amb l'arribada del Just, és a dir, del Messies i de la seva Bona Nova, s'acullen a l'esperança cristiana: "del Just en l'abraçada caberen els jerarques i generacions”.

\section{7. "Els patriarques"}

I Menats per la promesa d'una paraula pura anaven amb llurs dones, llurs fills i llurs ramats devers la incerta pàtria, la ignota sepultura, girant la cara als ídols i als reis de les ciutats.

s Quan els camells, en rengle, venien de l'aiguada i els grans vellards calmaven, seient, l'alè feixuc, a l'hora que ja tresquen batecs de marinada, Déu, llur amic, passava davant llur aixopluc.

I quan la nit, tendal de Déu, els protegia, Io ells, refiats de la paraula que els movia, comptaven la fillada futura estel a estel.

I atents a llurs ramades o en pensaments de guerra $\mathrm{Tu}$ sol, Tu sol, pregaven. Tu sol en cels i terra, I4 nuosos com la soca i tendres com la rel.

Aquest sonet havia romàs inèdit fins el I957: no pertanyia, fins llavors, a cap recull de poemes publicats en llibre per Carner. La seva temàtica bíblica, doncs, féu que fos inserit dins el recull anomenat Verb, que recopila versos d'aquesta característica.

Quant a la forma, és un sonet d'alexandrins, ${ }^{25}$ compost per dos quartets, de rima АВAB i CDCD, i dos tercets, de rima EEF i GGF. En tots els versos, la rima és consonant $i$ alternada: masculina en els versos parells i femenina en els imparells d'ambdós quartets. En els tercets, la rima és femenina, en els dos primers versos de cada tercet, i masculina, en el darrer vers de cada tercet. La cesura dels alexandrins és, normalment, a la sisena síllaba, i acostuma a coincidir amb la cesura sintàctica.

El poema se centra en la figura bíblica dels patriarques, seguidors del Déu únic, i guies del poble escollit envers la Terra Promesa, Canaan. En el darrer vers se'ls descriu, amb una comparació contraposada, com a "nuosos com la soca" i "tendres com l'arrel” (v. I 4). Són "nuosos” per la vellúria que els caracteritza, per la vida resseca del desert i pel dur nomadisme; però “tendres" per la seva humanitat i santedat, pel fet de ser novells en el seguiment de Jahvè, Déu únic, i l'acompliment de la seva Aliança. Són “soca” i “arrel” pel fet de ser precisament ells, els patriarques, el fonament, els caps i els guies del poble de Déu, 
un poble que, seguint la imatge de Carner, fóra simbolitzat pel brancam i el fullatge d'aquesta soca i d'aquestes arrels.

Aquest sonet subratlla dues qualitats que, en contraposició a la resta dels pobles, es troben presents en els patriarques: la creença en únic Déu (v. I3), allunyats de qualsevol culte pagà (v. 4), i la fe absoluta envers l'aliança feta amb Déu, quant a la descendència i a la Terra Promesa.

Els paral-lelismes bíblics es troben també presents en aquest sonet: així, el vers onzè remet al passatge bíblic de Gn. I 5, 5: "Després el Senyor va fer sortir Abram fora de la tenda i li va dir: -Mira el cel i compta les estrelles, si és que les pots comptar. Doncs així serà la teva descendència”.

Aquest sonet és una descripció dels patriarques, caracteritzats per la vida nòmada, de camí sempre cap a una terra promesa, per la seva fe en l'aliança de Déu, únic i omnipotent. La imatge antiga dels patriarques bíblics que se'ns descriu evoca al lector contemporani la imatge nòmada $\mathrm{i}$ errívola de tots aquells escriptors, intellectuals i polítics catalans que, com en el cas de Carner, es veieren obligats a exiliar-se de Catalunya durant la dictadura.

\section{8. "Els profetes"}

I Serveixen Déu (en l'ombra, on tant de cor flaqueja), les nacions vençudes, l'angoixa dels mesquins.-

En la cofurna humana, llur manament flameja, $\mathrm{i}$ amb una nit que invoquen esglaien els festins.

5 Condemnen les corones, la llei desfeta en xacres. Els porten aigua els núvols, les àguiles el pa. Així nodrits, aterren d'un mot els simulacres; llur solitud imposa l'imperiós demà.

Fang, per a Déu, profetes: un fang, d'Adam despulla, Io abans en toll sofert que el bestiar peülla, i que ja muda en llavis i cor la brasa ardent.

La mà que us redreçava us mena i us inspira: sou la misericòrdia roent, semblant a l'ira, I 4 que passa sobre els pobles com l'udolar del vent.

Aquest sonet d'alexandrins fou publicat dins el recull Primer llibre de sonets (Barcelona, I905), un recull de setanta-cinc sonets, d'entre els quals hi destaquen un grup de poemes religiosos. ${ }^{26}$ Aquests versos elogien la figura bíblica dels profetes, personatges encarregats de transmetre, amb la paraula, la voluntat de Déu al poble.

El sonet és format per dos quartets, de rima ABAB i CDCD, i dos tercets, de rima EEF i GGF. La rima és consonant i alternada: en els quartets, la rima és femenina, en els versos imparells, i masculina, en els parells. En els tercets, la rima 
és femenina, en els dos primers versos de cada tercet, $\mathrm{i}$, en el darrer de cada un, és masculina. En tots els versos, la cesura és de rima femenina i, com pertoca, cal collocar-la en la sisena sílllaba.

El sonet es divideix en dues parts; la primera, que comprèn els dos primers quartets, se centra en la caracterització de la figura dels profetes, entorn dels quals gira tot el sonet. Aquestes dues primeres estrofes, doncs, tenen com a subjecte una tercera persona del plural —una clara referència als profetes-, i descriuen les seves característiques pròpies: són servidors de Déu (v. I) i tenen un manament que sempre branda en flama i que perdura en l'estança de la misèria humana (v. 3).

En el vers quart, on s'hi diu "esglaien els festins", la força dels mots en aquest sintagma verbal ens remet a diferents passatges bíblics, en què la figura del profeta se situa en el marc d'un banquet reial. S'esdevé així en distints llibres bíblics, com és ara, per exemple, en el banquet del rei Baltasar del llibre de Daniel (Dn. 5), episodi en què el profeta dóna la correcta interpretació d'una inscripció misteriosa, no desxifrada fins llavors per cap dels savis d'aquells temps, al rei, o bé, en l'àmbit neotestamentari, el passatge del banquet del rei Herodes i la seva filla Salomé, famós per dur-s'hi a terme la decapitació de Joan Baptista (Mc. 6, I 4-29 i Mt. I4, I-I2). El passatge també recorda les paraules d'Isaïes (Is. 5, I I-I 2): “Ai dels qui de bon matí/ corren darrere la beguda/ i al capvespre s'atarden/ encesos pel vi!/ Mentre s'embriaguen al so de l'arpa,/ la lira, el tamborí i la flauta,/ no pensen què fa el Senyor,/ no s'adonen com actua la seva mà”.

El segon quartet subratlla, per una banda, la condemna que els profetes fan a les "corones", i.e., a les monarquies que són tiràniques i injustes amb el poble: és aquesta una lamentació recorrent en les paraules dels profetes. ${ }^{27}$ En el mateix vers cinquè també es remarca que són condemnadors de la llei "desfeta en xacres", el qual fet ens remet a distints passatges del llibre d'Isaïes (cf. Is. I, 26-27; Is. 5,23 i Is. IO, I-2). Els tres darrers versos de la primera part subratllen la vida solitària dels profetes ("els porten aigua els núvols, les àguiles el pa" v. 6; "llur solitud imposa l'imperiós demà”, v. 8).

La segona part del sonet és formada pels dos tercets restants. Els dos primers versos del primer tercet (vv. 9 i io) evidencien la realitat humana i efímera dels profetes: com en la resta dels homes, són, als ulls de Déu, al cap i a la fi, "un fang, d'Adam despulla/ abans en toll sofert que el bestiar peülla" (vv. 9-10).28 "La brasa ardent" que se cita en el vers i té una clara referència al passatge bíblic d'Isaïes $(6,6-7)$ on la purificació de la boca del profeta confirma la seva vocació i el prepara per a la missió: "Aleshores volà cap a mi un dels serafins duent a la mà una brasa que havia pres amb uns molls de damunt l'altar. Em va tocar la boca i digué: / —Ara que això ha tocat / els teus llavis, / ha desaparegut la teva culpa, / ha estat esborrat el teu pecat".

El sonet s'acaba amb un tercet ple de força i de musicalitat. S'hi subratllen dos aspectes: el primer, la importància de la mà divina en els profetes, la que els "mena i inspira", el qual fet el trobem clarament exposat en Jeremies ( $\mathrm{I}, 9)$ i en 
Daniel (ıо, I6): a l'Antic Testament, tal i com ha estat comentat, el braç i la mà són el signe del poder providencial, salvador o punitiu (cf. Ex. 6, 6; Dt. 5, I6; 2Sa. 24, I 5; Sl. 2 I, 9; Sl. 32, 4 i Is. 30, 30).

El segon, la misericòrdia dels profetes, tan característica, forta i "roent" com la ira (santa de Déu), ${ }^{29}$ que arriba a tots els pobles i que es deixa sentir "com l'udolar del vent". S'estableixen en aquesta darrera estrofa uns clars parallelismes conceptuals: per una banda, la brasa ardent, encesa per la mà divina, $\mathrm{i}$ la misericòrdia roent, que és semblant a l'ira, es relacionen, doncs, amb la força del vent que s'escampa per tot arreu i ho pot arrasar tot; per l'altra, la brasa ardent $\mathrm{i}$ la misericòrdia roent que mou el cor dels profetes, $\mathrm{i}$ que arriba a ells per voluntat divina, és el resultat sensible de la força en el vent, i.e., la seva veu, el seu brogit, el seu "udol”, de lamentació, queixa i compassió.

\section{El lèxic De la pOESIA bÍblica CARNERIANA}

Si la diversitat mètrica i temàtica és un tret constant en l'obra poètica de Carner, també ho és, parallelament, la riquesa lèxica i l'originalitat de llengua del poeta. Carner, com ja s'ha subratllat, és un mestre creador de versos i de llengua, i és en aquest sentit que M. Manent ( 52 l' l'elogia: “els poetes que més s'han distingit en el bon ús del ritme solen ser també grans mestres del llenguatge”.

En els nostres versos estudiats hi trobem mots i construccions pròpiament carnerianes. Quant a les particularitats lèxiques buscades pel poeta, noti’s el substantiu edem ("Cant de Raquel”, v. Io): és una variant formal forjada i emprada únicament per Carner, en lloc del mot d'origen hebreu Eden (cf. Alcover-Moll). La "mimació" (sufixació de la $m$ en els substantius, pròpia més aviat de l'hebreu clàssic) catalana enlloc de la "nunació" final (sufixació de la $n$ per a marcar les desinències del plural masculí en arameu), de ressò castellanitzant, sembla que sigui un canvi lèxic volgut i potser irònic de Carner..$^{3 \circ}$

Noti's també la utilització carneriana dels verbs denominatius: l'infinitiu 'terrejar' (> 'terra', “Cant de Raquel” v. 59) i el participi 'ventallat' ( 'ventall', “L’Eternal i el temple” v. 33).

Els mots llatinitzants i literaris, sense tradició vulgar, hi són també presents: és el cas de l'adjectiu 'vilipesa' "Cant de Raquel” v. 49), derivat del llatí vilipendere 'menysprear' ( $>$ tema de supí vilip nsum).

Els occitanismes medievals també hi són presents, com és el cas del substantiu drudes (“Cant de Raquel”, v. 4I), “amant, amistançat”, mot que no és pròpiament català, ans un manlleu occità dels trobadors (veg. J. Coromines, vol. 3, 2 I 2).

També hi trobem dialectalismes geogràfics: el substantiu curculla ("cadascuna de les closques bibalves d'una petxina”), al "Cant de Raquel” (v. 49), d'ús dialectal a l'Empordà i al Gironès; així com també l'ús del diminutiu en l'adjectiu solin ("Cant de Raquel”, v. Io), propi de la varietat eivissenca. 


\section{Conclusions}

Aquí s'acaba l'estudi d'aquells poemes carnerians editats dins la collecció Verb, que, juntament amb Nabí, es poden titllar de "veterotestamentaris" i, a la vegada, de "parabíblics", en el sentit que són composicions que coneixen el text bíblic i sorgeixen arran d'ell, però que van més enllà del text originari, car hi afegeixen tradicions distintes $i$ aportacions pròpies de l'autor. Les composicions d'aquest recull, doncs, interpreten el text bíblic i, a la vegada, prolonguen el text amb elements nous d'altres tradicions.

Les vuit peces poètiques just acabades de comentar, per tant, tenen la característica d'evocar i recrear, cadascuna d'elles, algun passatge o algun protagonista de l'Antic Testament. No obstant això, tot i compartir aquest tret comú, tant la mètrica com el contingut són, entre si, força distints: així ho són també, entre si, per forma, contingut i llengua, els diferents llibres de la Bíblia.

Quant a la temàtica i a les referències bíbliques, es troben referències clares a cadascuna de les tres parts bàsiques en què es divideix la Bíblia Hebrea: el Pentateuc, els Llibres profètics i els Escrits. Així, en algun dels episodis del Pentateuc, s'hi troben inspirats els "Cants de Caïm i d'Abel”, on s'hi rememora el passatge de Gènesi 4, I-I6 i el "Cant de Raquel”, un càntic de lloança que se situa just abans de l'episodi narrat en Gènesi 29, I-30. Amb l'“Espera dels patriarques" i "Els patriarques" s'al-ludeix també als personatges protagonistes dels llibres del Gènesi i de l'Èxode.

“L'Eternal i el temple" té, com a petja de rerafons, un dels llibres profètics, concretament, el passatge bíblic de 2 Sa. 6-7, que narra el trasllat de l'arca de l'Aliança a Jerusalem, el pla de construcció del temple ideat per David i el seu rebuig per part de Jahvè.

El sonet "Els profetes" exalça la figura bíblica dels profetes: s'hi pot anar resseguint una clara influència del llibre d'Isaïes, paradigma bíblic del profetisme, $i$ algun passatge del llibre de Daniel.

Finalment, les composicions "Cant del just" i "Salm de la captivitat" són poesies que tenen un clar parallelisme amb el contingut i la forma dels salms. El "Cant del just" és un salm bíblic de pregària, en què es poden resseguir clars parallelismes de contingut amb el conegut Salm 23. El "Salm de la captivitat", per altra banda, recorda la lamentació d'enyorança de Sió, des de l'exili babilònic, present en el Salm I 37 ("Vora els rius de Babilònia").

Si la temàtica i la influència bíblica, doncs, són distintes i variades entre si, també s'esdevé el mateix en parlar de la mètrica emprada en aquestes composicions. El poeta hi utilitza versificació sillàbica i estròfica diferent en cada peça. L'estrofa que més hi abunda és la formada per quartets, que, en el "Cant de Raquel”, s'alternen amb quintets i, en "L'espera dels patriarques" i "Els patriarques", juntament amb els dos tercets d'alexandrins, formen part integradora del sonet. Quant a la versificació, el decasílllab i l'alexandrí són els versos més emprats en aquestes peces.

Com a característica mètrica carneriana, cal tenir present la composició 
“L'espera dels patriarques". Cada estrofa és un quartet format per tres versos de divuit síllabes; cada vers del quartet, doncs, llevat del darrer que és un dodecasíllab, és integrat per tres hexasíllabs: és un exemplar mètric únic en Carner.

Hem vist, doncs, que la diversitat temàtica i mètrica és una constant en aquest recull de poesies: l'eix vertebrador que les uneix és, precisament, el rerafons bíblic. La riquesa temàtica, mètrica $i$ lingüística d'aquestes vuit composicions, que, juntament amb Nabi, formen els dos reculls del que hem anomenat literatura "parabíblica” carneriana, són un bon exemple dels trets poètics de Carner: imaginació, geni de llengua, creació, sensibilitat, domini mètric i rítmic, força poètica i bagatge cultural i literari. Totes aquestes qualitats són les que van sorgint, juntament amb la fe, arran de la lectura d'aquests vuit poemes. Són vuit peces poètiques ben distintes entre elles, però unides per una mateixa tradició: l'Antic Testament.

\section{EULÀLIA VERNET I PONS \\ UNIVERSITAT DE BARCELONA}

\section{REFERÈNCIES}

Alcover, Antoni M. i Francesc de B. Moll. Diccionari català-valencià-balear. Palma de Mallorca, I993.

Aulet, Jaume. L'obra de Josep Carner. Barcelona: Teide, I991.

Bíblia Catalana. Traducció interconfessional. Associació Bíblica de Catalunya.

Societats Bíbliques Unides. Barcelona: Editorial Claret, I994.

Bou, Enric; Jordi Castellanos; Salvador Oliva et alii. Josep Carner. Llengua, prosa, poesia. Barcelona: Empúries, 1985.

Cardona, Osvald. "Ell i el poeta (Els temes de Josep Carner)". De Verdaguer a Carner. Assaigs sobre l'afinitat entre grans poetes. Barcelona: Selecta, 1960.

- El temps de Josep Carner (I 899-I922). Barcelona: Dalmau, I967.

Carner, Josep. Obres completes. Poesia. Barcelona: Selecta, I957.

Coll, Jaume. “Introducció”. Josep Carner, Poesia (text de l'edició de 1957 revisat i establert per Jaume Coll). Barcelona: Quaderns Crema, I992.

Coromines, Joan. Diccionari etimològic $i$ complementari de la llengua catalana. Barcelona: Curial i Caixa de Pensions "La Caixa", I995.

Even-Shoshan, Avraham. A new Concordance of the Old Testament. Jerusalem, I993.

Hurushowski, H. "Prosody". Enciclopaedia Judaica I 3 (I972): I 2 I I-I 220.

Manent, Albert. Josep Carner i el noucentisme. Vida, obra i llegenda. 2a. ed.. Barcelona: Edicions 62, 1982.

Manent, Albert et alii. Josep Carner en els seus millors escrits. Barcelona: Miquel Arimany, 1984 .

Manent, Marià. "Pròleg". Josep Carner, obres completes. Poesia. Barcelona: Selecta, I957. 
Millàs i Vallicrosa, Josep M. La poesía hebraica postbíblica. Barcelona, I953. Müller, David H. von. Die Propheten in ibrer ursprunglichen Form. Viena: Hölder, I 896.

-. Strophenbau und Responsion in Ezechiel und den Psalmen. Viena: Hölder, I908.

Porcel, Baltasar. “Josep Carner: L’alta permanència”. Serra d’Or 8 (ig66): 949-957.

Santaeulàlia, J. N. “Quatre modalitats en la poesia de Josep Carner”. Catalan Review 6 (1992): 325-369.

SCHREIBER, R. "Verb: anàlisi i intent d'interpretació". Catalan Review 6 (1992): $285-323$.

Subirana, Jaume, ed. Carneriana. Josep Carner, vint-i-cinc anys després. Barcelona: Proa, I995.

Wright, William. "Prosody". A Grammar of the arabic language. $2 \mathrm{n}$ vol: $350-$ 390. Cambridge: Cambridge UP, I964.

\section{Notes}

I Vegeu, en aquest sentit, M. Manent: "No hi manquen els motius mitològics ni la influència bíblica, que han persistit tot al llarg de l'obra de Josep Carner" (22); i també A. Manent et alii, "La formació i la voluntat cristianes de Carner són una altra de les constants que descobrim en el seu capteniment, en els seus poemes religiosos” (I I).

${ }^{2}$ M. Manent: "Si en molts llibres de Carner hi ha temes bíblics, Nabí és, en aquest sentit, l'esforç més remarcable: un llarg poema inspirat en un episodi de l'Antic Testament, en alternança d'acció i de reflexió, però tot endut en un ritme narratiu infallible i desplegant-se en un llenguatge que és com la destilllació més pura d'una llarga experiència poètica” (43).

3 Quant a l'edició de i957, cf. A. Manent et alii: “La publicació per Editorial Selecta de Barcelona de les seves Obres completes. Poesia (1957) és un esdeveniment, sobretot després d'haver sofert Carner l'ostracisme polític i, en part, el literari, ja que la seva lírica fou desvalorada pel crític, els criteris del qual imperaven aleshores. Carner torna a ésser present en el món de les lletres catalanes, bé que en llibertat vigilada i ni que sigui de lluny" (2 I).

${ }_{4}$ Aquest títol de llibre farà referència, d'ara en endavant, a la publicació de l'obra poètica completa de Josep Carner feta l'any i 957 per l'editorial Selecta.

s Quant a la vida de Josep Carner, remeto el lector a l'obra indispensable d'A. Manent (Josep Carner i el noucentisme) i també a la d'O. Cardona (El temps de Josep Carner). Pel que fa als estudis generals de l'obra i l'estil del nostre poeta, veg. les obres de J. Aulet, E. Bou et alii, A. Manent et alii, J. Subirana ed., entre d'altres.

6 "La polèmica sobre la revisió i l'agrupació temàtica dels poemes no tan sols va impedir en el seu moment una valoració justa de Poesia, sinó que, de retop, va relegar al silenci el centenar de poemes inèdits que Carner hi donava a la llum, als quals cal sumar els 44 poemes que fins llavors havien estat publicats en diaris i revistes -la majoria d'aquests poemes foren escrits durant les dècades dels 40 i 50 " (Santaeulàlia 325 ).

7 "Només dues úniques seccions es poden considerar tancades, configurades des d'un principi i no alterades en la recompaginació: els Fruits saborosos i Nabí, reculls que 
no contenen poemes incorporats o substituïts respecte els llibres primers, sinó que conserven les característiques de les edicions primeres. Segurament que també es pot considerar tancada des d'un principi una tercera secció: Verb, que, a diferència de les altres dues, no és una collecció fundada només en un llibre anteriror, sinó que és un recull format per poemes de diversa procedència. Verb té el caràcter d'un llibre tancat, una arquitectura que no admet absorcions, $\mathrm{i}$, en tal cas, difícilment podia estar subjecta a canvis en el nombre $\mathrm{i}$ en la disposició, donada la seva solidesa tan perfectament travada i compacta (en cap carta no s'esmenta, per exemple, cap poema susceptible de ser-hi incorporat, cap indicació que pugui fer pensar en una mínima correcció del conjunt). Totes les altres seccions, les altres deu seccions, van ser sotmeses a canvis més o menys profunds" (Coll 33).

8 Les sigles que acompanyen els poemes publicats anteriorment corresponen als reculls següents: $\mathrm{JFB}=$ Jocs Florals de Barcelona, I903; Cor $=$ Corones, 1904 ; PrS $=$ Primer llibre de Sonets, I905; Mon = Les monjoies, I91 2; OrC = L'oreig entre les canyes, I920; CoQ = El cor quiet, I925; i els poemes no publicats en forma de llibre = NPL.

9 Quant a la cita dels llibres bíblics, segueixo les mateixes abreviatures fixades en la Bíblia Catalana. Traducció Interconfessional (I994). En concret, pertanyents a l'Antic Testament, se citen els llibres següents: Coh., Cohèlet; ${ }_{\mathrm{I}} \mathrm{Cr}$., Ir Cròniques; $2 \mathrm{Cr}$., $2 \mathrm{n}$ Cròniques; Dn., Daniel; Dt., Deuteronomi; Ex., Èxode; Ez., Ezequiel; Gn., Gènesi; Is., Isaïes; Jb., Job; Jo., Jonàs; Ne., Nehemies; Rt., Rut; ISa., Ir Samuel; 2Sa., 2n Samuel; Sl., Salms. Pertanyents al Nou Testament, se citen els llibres següents: 2 Co., 2 a Corintis; He., Hebreus; Jn., Joan; Lc., Lluc; Mc., Marc; Mt., Mateu. Així mateix, la traducció catalana dels passatges bíblics són extrets d'aquesta mateixa edició.

1o El caràcter de rebelllió i disconformitat de Caín amb relació a Déu i el rebuig que ha sofert, quant a la seva ofrena, es palesa així en Gn.4, 4-7: "El Senyor va acollir favorablement Abel i la seva ofrena, però no acollí Caín i la seva. Caín es va irritar molt $\mathrm{i}$ anava amb el cap baix. El Senyor li digué: - Per què estàs irritat i no aixeques el cap? Si obres bé, seràs acceptat; però, si no obres bé, el pecat aguaita a la porta: ell et desitja, però tu l'has de dominar".

II “Jo sóc el bon pastor. El bon pastor dóna la vida per les seves ovelles”.

12 Els antagonismes entre els pastors nòmades i els agricultors són ancestrals. He. I I, 4 vol donar una explicació d'aquest refús de l'ofrena parlant de la fe d'Abel: “Gràcies a la fe, Abel va oferir a Déu un sacrifici millor que el de Caín. Per aquesta fe, Abel va rebre el testimoni que era just, ja que Déu va acceptar els dons que li oferia. Ell va morir, però la seva fe encara parla”.

13 En les llengües semítiques, i concretament en hebreu i en arameu, aquest terme fa referència a l'adjectiu "blanc", o bé, també, a la "lluna".

${ }^{14}$ Aquest darrer epítet de Déu, apareix en la Bíblia Hebrea uns vuit cops, segons les concordances d'Even-Shoshan: segons aquestes concordances, l'epítet apareix com a lwh hšmym als llibres bíblics següents: Gn.24, 3.7; Jo. I, 9; Ez. I, 2; Ne. I, 4-5 i 2, 4.20; ${ }_{2} \mathrm{Cr}$. 36, 23. Amb l'epítet d'?l hšmym, apareix únicament al Salm i 36, versicle 26.

is "Ja no et diràs més Abram: el teu nom serà Abraham, perquè et faré pare d'una multitud de pobles. Et faré molt i molt fecund; els teus descendents formaran diverses nacions, $\mathrm{i}$ de tu sortiran reis".

I6 "Si bé la interpretació eclesiològica de Raquel no és nova i també el Josep egipci havia estat tingut per una prefiguració de Crist ja des de Tertulià, és ben original que Carner faci que s'uneixin dos corrents tipològics tradicionals: Raquel, com a mare de Josep -la figura Christi-, és alhora figura Mariae i typus Ecclesiae” (Schreiber 3 I6).

${ }_{17}$ Cf. Ex. 25, 22: "Allà et vindré a trobar, i des de la coberta, entre els dos querubins que hi ha damunt l'arca que conté el document de l'aliança, et comunicaré totes les ordres destinades als israelites". 
I8 Quant al tema de la poesia bíblica i semítica, veg., entre d'altres, H. Hurushowski, J. M. Millàs, D. Müller (Die Propheten i Strophenbau und Responsion) i W. Wright.

19 "I Déu va afegir: -El signe de l'aliança que faig amb vosaltres i amb tots els éssers vius que us envolten, per totes les generacions i per sempre, és aquest: posaré el meu arc en els núvols com a signe de la meva aliança amb la terra. Quan jo cobreixi de núvols la terra i entre els núvols aparegui el meu arc, recordaré l'aliança que he fet amb vosaltres i amb tots els éssers vius, i les aigües del diluvi no tornaran a destruir ningú. Sortirà l'arc en els núvols i, en veure'l, recordaré l'aliança perpètua, la meva aliança, la que hi ha entre Déu i tots els vivents, tots els qui viuen a la terra. Déu va dir a Noè: -Aquest és el signe de l'aliança que he fet amb tots els qui viuen a la terra".

${ }_{20}$ Compari's aquests dos darrers versos amb iCo. I s, 26: rere l'estreta porta de la mort es deixa de banda, doncs, el dolor.

${ }_{21}$ "Però n'hi ha prou amb una lectura superficial per adonar-se que, més que un poema religiós, es tracta d'un poema d'exili” (Santaeulàlia 345). I quant a l'últim quartet, Santaeulàlia es limita a comentar únicament el següent: "El poema-salm es clou amb una gairebé previsible alllusió a la mort; fins i tot aquí, però, hi regna l'esperança” (346). De fet, precisament, però, és el darrer quartet l'estrofa més substanciosa i la que dóna sentit global al poema.

${ }^{22}$ Proposo la lectura "com a ròssecs", és a dir, afegint la preposició “a” en aquet sintagma preposicional comparatiu, car permet, mètricament, el còmput de l'hexasílllab, obligatori en aquest darrer hemistiqui del vers.

${ }_{23}$ L'anàlisi mètrica que Schreiber (3 I I) fa del poema no s'adequa a la realitat sillàbica de la composició.

${ }_{24}$ Quant a l'humor carnerià, veg. A. Manent (I 59-I64).

${ }_{25}$ El sonet d'alexandrins prové de la literatura francesa medieval: el sonet tradicional és fet de decasíllabs.

${ }^{26}$ Quant a la utilització del sonet per part de Josep Carner, cf. M. Manent (47) i també A. Manent et alii (I 3 ).

${ }^{27}$ En aquest sentit, vegi's els passatges següents del llibre d'Isaïes: 5, I3; IO, I 2; I 4, 4-8 - una sàtira contra el rei de Babilònia-; I 4, 25 i i 7 -n contra els regnes de Damasc i d'Israel.

${ }_{28}$ Quant a aquest darrer vers, cf. Is. 5, I7: "Per les ruïnes dels palaus dels rics/ pasturaran els ramats, / el bestiar de pas s'hi atiparà”.

${ }_{29} \mathrm{Cf}$, en aquest sentit, Is IO, I7: "El Déu sant, llum d'Israel,/ serà foc i flama/ que en un sol dia/ li cremarà i consumirà/ les espines i els esbarzers”.

$3^{\circ}$ Com a anècdota biogràfica, sabem que Carner va estudiar, com a mínim, una assignatura d'hebreu i que, tot i que el catedràtic d'hebreu d'aleshores fos un "trencacolls" i el suspengués tant al juny com al setembre, l'acabà aprovant al juny de i903. En aquest sentit, veg. A. Manent (26). 